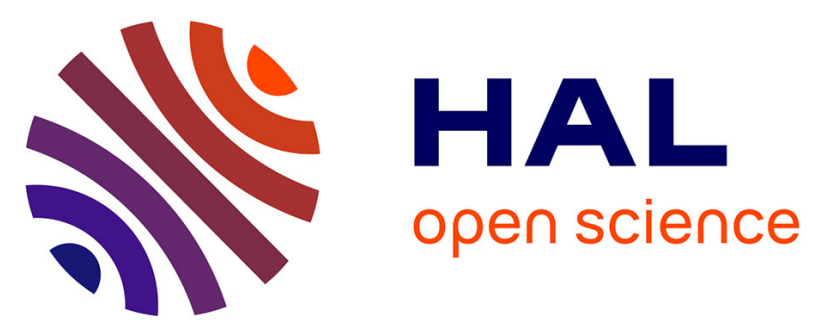

\title{
Production Planning in Intra-organizational Network - A Study Under the Point of View of Annotative Paraconsistent Logic
}

Fabio Papalardo, Fabio De Carvalho, Jose B. Sacomano, Jayme Aranha Machado

\section{To cite this version:}

Fabio Papalardo, Fabio De Carvalho, Jose B. Sacomano, Jayme Aranha Machado. Production Planning in Intra-organizational Network - A Study Under the Point of View of Annotative Paraconsistent Logic. IFIP International Conference on Advances in Production Management Systems (APMS), Sep 2015, Tokyo, Japan. pp.211-218, 10.1007/978-3-319-22756-6_26 . hal-01417473

\author{
HAL Id: hal-01417473 \\ https://hal.science/hal-01417473
}

Submitted on 15 Dec 2016

HAL is a multi-disciplinary open access archive for the deposit and dissemination of scientific research documents, whether they are published or not. The documents may come from teaching and research institutions in France or abroad, or from public or private research centers.
L'archive ouverte pluridisciplinaire HAL, est destinée au dépôt et à la diffusion de documents scientifiques de niveau recherche, publiés ou non, émanant des établissements d'enseignement et de recherche français ou étrangers, des laboratoires publics ou privés.

\section{(c)(1)}

Distributed under a Creative Commons Attribution| 4.0 International License 


\title{
Production Planning in Intra-organizational Network - A Study under the point of view of Annotative Paraconsistent Logic
}

\author{
Papalardo Fabio ${ }^{1}$, de Carvalho F.R ${ }^{1}$, Sacomano B. Jose ${ }^{1}$, Machado J.A ${ }^{1}$ \\ ${ }^{1}$ Paulista University-UNIP, Post-Graduate Program in Production Engineering, São \\ Paulo, Brazil \\ \{Fabio Papalardo, fabio.eng.unip@gmail.com\}
}

\begin{abstract}
Competitiveness among enterprises, acting within global sustainability, has resorted to several types of administration in order to keep companies in the vanguard of the market. One of the most efficient types of administration is effective Planning, in such a way as to perform a task at the minimum time required and the lowest possible cost.Planning has become ever so complex, due to the innumerable demands from technology and market. A relevant aspect of Planning is that the sectors that influence it, whether productive or not, compound a chain of influences that will determine either success or failure of such Planning.One manner to tackle a network matrix analysis is by Para- consistent Logic, a mathematical model that does not follow Classic Logic.It was then possible to verify the efficacy of this model of Planning analysis, as a method to be used and studied and subsequently adopted and used.
\end{abstract}

Keywords.Planning, Networks of Companies, Paraconsistent Logic

\section{Introduction}

The globalization phenomenon has brought into the market ever more so the competitiveness among companies and countries, and, in order to maintain sustainable management, new administration models are necessary.

Innovative companies need agile action towards products and services in order to respond quickly and explore new conditions. This agile action, however, must be systematic [1].

At the industrial area, further to the development of new equipments and new technologies, the administration of Production Planning has become much more complex to face demands from market and new technologies.

One of the ways of analyzing this aspect is under the point of view of Networks of Companies; specifically, as far as Production Planning the analysis is done, an Intraorganizational Network.

Within an organization, and among organizations, there must be resource and knowledge channels, and these can be studied as a network [2].

The study of resource channels can be analyzed in various manners, always keeping in mind that an intra-organizational network has its matrix aspect, as a company's 
sectors or departments do form among themselves a matrix network of interdependency.

Analysis resources, like Statistics, Matlab, Ucinet and others, have been studied for a wider vision of Production Planning.

In this work we shall introduce Annotative Paraconsistent Logic in order to visualize a scenery that presents all sectors involved in the industrial process, so to permit efficient Planning, as well as Control aspects to make sure that all planned requisites are kept during production.

\section{Theoretic Foundation}

\subsection{Production Planning}

The most important aspect of the context of development and maintenance of a control and planning production system perhaps is the continual change at the competition approach, and such changes should occur from the technological to the strategic and the legal areas [3].

Along with technological development and a wide range of market strategies, as well as alterations of pertinent legislation due to globalization, Production Planning becoming ever more complex, as the number of variables increases systematically and some of these variables may be subject to alteration or even beyond assessment.

Independently of the type of manufacture or manufacturing system, Planning is an essential factor to the success of the task. Traditional systems, as ERP and others are no longer sufficient for a safe and effective planning. Various ERP projects draw into tangible and intangible developments, considerable in different areas, and to attain competitive advantages for organizations; nevertheless there are several histories of failures as companies use ERP [4].

Therefore, new thinking manners, new organizational formats and new logic reasoning must be implemented in order to keep a company competitive as it operates inside an ever changing universe.

\subsection{Company Network}

One way of planning and analyzing an organization is to look at it as it were a network, that is, where sectors or departments involved in the production process are seen as actors of this task.

The notion of network organization implies the need to rethink the limits of a sector separately, emphasizing the importance of the several types of relationship it has with other actors and institutions [5].

The connection or influence that a sector or actor applies into another must be taken into consideration, so that it is possible a more global view of the process, instead of a static vision of each department by itself. 
Obviously each sector receives and exerts different influence over another. The network study defines as central, the department or actor under scrutiny, and proceeds to identify how the other sectors receive and exert influence over it.

In this work, Planning is considered as central to a network, and the actors are: Sales; Product Project; Industrial Engineering or Processes; Production; Quality; Purchasing and Planning, the central agent.

The intensity of relationship between actors is called "density" and it shows the degree of influence of a sector over another. The assessment of density is important to quantify the network.

Networks inside an organization and between organizations must work as a channel of resources and knowledge. It has been found out that the proprieties of regional clustersshow marked differences, which intensify as the size of the network increases. It also became evident that companies connect themselves in different modules; thereforenetwork activity must focus on different modules, in order to support the development of networks [2].

The network performance, as far as the flux of resources and knowledge, can be improved by adding connections inside an organization [6].

Meaningful role in these relationships is the strengthening of the links of experience and knowledge of the central. Added knowledge affects positively the company's competitiveness [7].

\subsection{Paraconsitent Logic}

In order to analyze an inter-organizational network company, we shall adopt a non classical logic, the so called paraconsistent logic.

Operations in models that tolerated the presence of inconsistencies are vital to uphold solutions of particular designs [1].

In annotated paraconsistent logic, one proposition $\mathrm{A}$ can be expressed by a matrix $(\mu ; \lambda)$, where $\mu$ is the degree of belief $A$ and $\lambda$ is the degree of disbelief that is, A. Let us consider the maximum degree as one (1) and the minimum as zero (0). Therefore, a proposition A can be expressed by symbol "p", denoting upp $\mathrm{u}_{\mathrm{A}}(1 ; 0)$, that is, the grade of belief maximum and a grade of non belief minimum; on the other hand, the denial of A can be expressed by the symbol $\neg \mathrm{p}_{\mathrm{A}}(0 ; 1)$, and reflects, by definition $\neg \mathrm{p}_{\mathrm{A}}(0 ; 1)$ $\leftrightarrow \mathrm{p}_{\mathrm{A}}(1 ; 0)$

In paraconsistent logic may be evidence with degree of belief or disbelief different from the maximum (one), or the minimum (zero), i.e., there may be belief and disbelief in a proposition A.Placed in a Cartesian diagram, with the degree of belief in $\mathrm{x}$ axis and the $y$-axis in disbelief, all the notes are a unit square (Fig. 1 left side), where are highlighted the extreme points and the point $(0.6,0.2)$. Importantly, the sum of two parameters $\mu$ and $\lambda$ will not always be 1 (one) as common sense would indicate, since the degrees of belief and disbelief may be independent of each other, for example, a belief factor can be favorable to time execution of a task, and their degree of disbelief can be affected in relation to the delivery time from a vendor.

Therefore we can have extreme situations in which $\mathrm{p}_{\mathrm{A}}(0 ; 0)$ or also $\mathrm{p}_{\mathrm{A}}(1 ; 1)$. In the first case, there is no evidence of belief or non belief, that is, there are no available 
information and this extreme situation we call "undetermined". The other case we have evidence of maximum belief and, at the same time, evidence of maximum non belief, which we cal "inconsistent". The above extreme cases along with the concepts of classical logic - in it we call $\quad \mathrm{p}_{\mathrm{A}}(1 ; 0)$ "Truthful", as the evidences of belief are maximum and non belief are minimum, and the negative of it $\mathrm{p}_{\mathrm{A}}(0 ; 1)$ we call "False", as it denies the Truthful.One point may be closer or more distant from the extremes. It gives us a visual idea of the trend: Truthfulness, Falsity, Inconsistency or Indetermination. Of course the ideal is to have an affirmation the closest possible to the extreme point $\mathrm{p}_{\mathrm{A}}(1 ; 0)$ - Truthful. So, is defined the "Degree of Certainty": it indicates where we are positioned in relation to the ideal $\mathrm{p}_{\mathrm{A}}(1 ; 0)$. The degree of certainty is defined by the equation $\mathrm{H}=\mu-\lambda$. Graphically, the degree of certainty is expressed by a line in the graphic.

This is an example that we will use in our methodology. $\mathrm{H}=0,7$. Many combinations may result in $\mathrm{H}=0,7$, that is, $\mathrm{p}_{\mathrm{A}}(1 ; 0,3)$ or $\mathrm{p}_{\mathrm{A}}(0,9 ; 0,2)$ or $\mathrm{p}_{\mathrm{A}}(0,8 ; 0,1)$ or $\mathrm{p}_{\mathrm{A}}(0,7 ; 0)$ and many others.

For the analysis of this work will be considered the region of the unit square, defined by $M \geq 0.7$, called certainly region (Fig. 1 right side)

Fig. 1. Cartesian Diagram
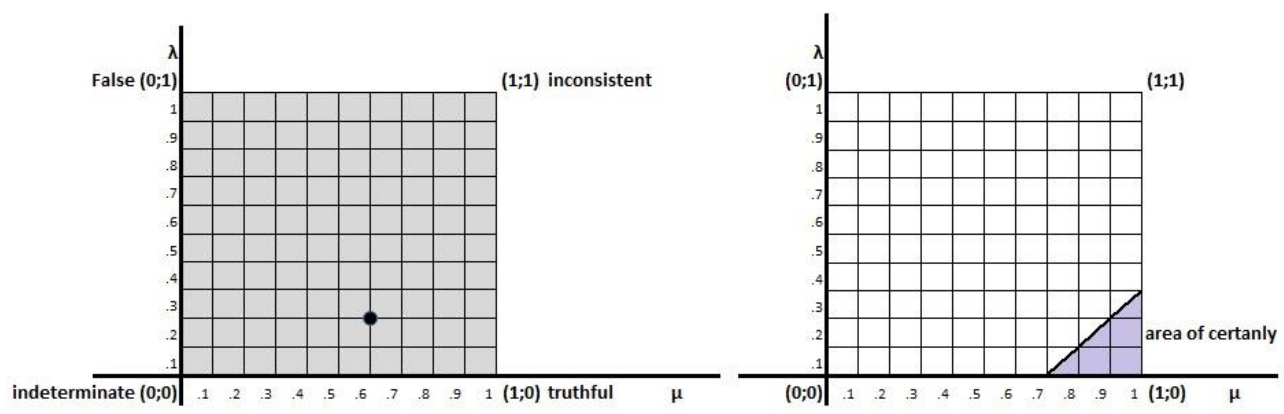

\section{$3 \quad$ Methodology}

The present investigation involved structured interviews with specialists in the areas of Sales, Product Project, Fabrication Processes, Manufacturing, Quality, Purchasing and Planning. The company that was selected is an industry of capital goods, producer of drilling equipment and fluids pumping. Any product is usually "customized", and this is determinant that each product is manufactured just once. Consequently, Planning is essential for low cost and minimum production time, as there is no possibility of improving planning for next production. Interviews were conducted with specialists of managerial rank, one of each area, except the production, for which we interviewed two specialists. Such was necessary because this department is the most sensible to variations of the planning sector, and that is the reason to obtain two opinions of the production area. The criterion adopted for analysis is that each specialist answered questionsalways through a matrix $(\mu ; \lambda)$ and added notes explaining reasons 
why he had indicated the degrees of belief or non belief. Data was organized in a table. The results indicated by specialists from the same area, in this case, the production, were considered through the disjunction criterion $(\mathrm{V})$, where, $\mathrm{p}_{1}\left(\mu_{1} ; \lambda_{1}\right) \mathrm{V} \mathrm{p}_{2}\left(\mu_{2}\right.$; $\left.\lambda_{2}\right) \rightarrow \mathrm{p}_{1}$ or $2\left(\mu_{\max } ; \lambda_{\min }\right)$. Results from specialists of different areas were considered through the conjunction criterion $(\wedge)$, where, $\mathrm{p}_{1}\left(\mu_{1} ; \lambda_{1}\right) \wedge \mathrm{p}_{2}\left(\mu_{2} ; \lambda_{2}\right) \rightarrow \mathrm{p}_{1 \text { or } 2}\left(\mu_{\text {mim }}\right.$; $\left.\lambda_{\max }\right)[8]$

The minimum degree of certainty chosen for this work was $\mathrm{H}=0,7$. Observing the Figure 2 it appears that the area corresponding to the real area (or certain favorable), we verify that the area in the certainty zone is the area of a triangle $0,3 \times 0,3 / 2$, that is a surface of 0,045; graphic total area is the surface of a square $1 \times 1$, or a surface of 1 . The percentage of the certainty area as related to the total surface is $1-(0,045 / 1)=$ 0,955 and the certainty is $95,5 \%$, and this is a good number as far as planning is concerned. It is worthy to mention that for more restricted values above 0,7 the costs for the functioning of the network can be very high.

The question brought up was: "How do you classify the condition of the analyzed item?"

The analyzed items were determined by all the consulted specialists through non structured interviews in order to determine the influences of each department over the Planning, considered as the center of the intra-organizational network in this study.

For a better assessment, each particular question was divided into three parts, each corresponding an interval of the degree of certainty: within the target $0,7 \leq \mathrm{H} \leq 1$ (a); with relative degree of acceptance $-0,7 \leq \mathrm{H} \leq 0,7$ (b); with no acceptance at all $-1 \leq \mathrm{H}$ $\leq 0,7$ (c), as we can see in the following list of statements:

SALES: - "Program Trends": Stable (a); Increase (b); Decrease (c)

PROJECT PRODUCT: - "Benchmarking": Very Competitive (a); Somewhat Competitive (b); Hardly Competitive (c) / "Detailed Description": High Level Complexity (a); Medium Level Complexity (b); Low Level Complexity (c)

PROCESSES: - "Method" and "Equipment": Modern and Up to Date (a); not so Modern (b); old (c)

PRODUCTION: - "Lay Out": Functional (a); Not so Functional (b); Difficult to handle and operate (c) / "Training": Periodic Training Program (a); Eventual Training Program (b); No Training Program (c) / "Kan Ban": Installed (a); Installation in Progress (b); No Kan Ban (c)

QUALITY: - "Quality System": Installed (a); Installation in Progress (b); No Quality System (c) / "Statistic Process Control": Installed (a); Installation in Progress (b); No Quality SPC (c)

PURCHASING: - "Just in Time": Installed (a); Installation in Progress (b); No JIT (c) PLANNING PRODUCTION CONTROL: - "PPC": Agile - Quite efficient (a); medium (b); slow off poor performance (c)

Once completed the research, the marks determined by $\mu$ and $\lambda$ were plotted on the graphic. The set of points permits a graphic idea of the network. The total influence of the 12 factors considered is indicated as the gravity center of the network; each point is a knot in a net and the gravity center is the resultant effect of the knots or the center of them [8]. 
To each knot was assigned the same importance; therefore there are no different values (weights) to add to a knot in order to calculate the gravity center. In case a knot exerts influence of a different weight over the gravity center, a weighted average must be calculated. In this case, the arithmetic mean was also calculated and it did coincide with the weighted average. Therefore, we come up with the global results and hence the present scenario for the sector of Planning.

\section{$4 \quad$ Result and Discussion}

After the research the results were found, and according to the disjunction criterion (V) among specialists of the same area - Production, we have $\mathrm{p}_{1 \operatorname{prod}}\left(\mu_{1} ; \lambda_{1}\right) \mathrm{V} \mathrm{p}_{2 \operatorname{prod}}\left(\mu_{2}\right.$; $\left.\lambda_{2}\right) \rightarrow p_{\text {lou } 2}\left(\mu_{\max } ; \lambda_{\min }\right):$

Fig. 2. Results Disjunction Criteria

\begin{tabular}{|c|c|c|c|c|c|c|c|c|c|c|c|c|c|c|c|}
\hline & & \multirow{2}{*}{\multicolumn{2}{|c|}{$\begin{array}{c}\text { Sales } \\
\text { Expert } 1\end{array}$}} & \multirow{2}{*}{\multicolumn{2}{|c|}{$\begin{array}{l}\text { Product Project } \\
\text { Expert 2 }\end{array}$}} & \multicolumn{2}{|c|}{ Processes } & \multicolumn{2}{|c|}{ Production } & \multicolumn{2}{|c|}{ Quality } & \multicolumn{2}{|c|}{ Purchasing } & \multicolumn{2}{|c|}{ PPC } \\
\hline & & & & & & & & Inte & & & & & & & \\
\hline & & $\mu$ & $\lambda$ & $\mu$ & $\lambda$ & $\mu$ & $\lambda$ & $\mu$ & $\lambda$ & $\mu$ & $\lambda$ & $\mu$ & $\lambda$ & $\mu$ & $\lambda$ \\
\hline Sales & Program trends & 1 & 0 & 0,8 & 0,2 & 0,8 & 0,3 & 0,8 & 0,2 & 0,8 & 0,3 & 1 & 0 & 0,9 & 0,3 \\
\hline \multirow{2}{*}{\begin{tabular}{|l|} 
Product \\
Project \\
\end{tabular}} & Benchmarking & 0,8 & 0,3 & 1 & 0 & 0,8 & 0,2 & 0,8 & 0,2 & 0,8 & 0,3 & 0,8 & 0,2 & 1 & 0 \\
\hline & Detailed Description & 1 & 0 & 1 & 0 & 1 & 0 & 1 & 0 & 1 & 0 & 1 & 0 & 1 & 0 \\
\hline \multirow{2}{*}{ Processes } & Method & 0,8 & 0,3 & 0,8 & 0,2 & 1 & 0 & 1 & 0 & 0,8 & 0,2 & 0,8 & 0,2 & 1 & 0 \\
\hline & Equipment & 0,8 & 0,2 & 1 & 0 & 1 & 0 & 1 & 0 & 0,8 & 0,2 & 0,7 & 0,3 & 1 & 0 \\
\hline \multirow{3}{*}{ Production } & Lay Out & 0,8 & 0,2 & 0,8 & 0,2 & 0,8 & 0,2 & 0,8 & 0,2 & 0,8 & 0,2 & 0,9 & 0,2 & 0,8 & 0,2 \\
\hline & Training & 0,8 & 0,3 & 0,9 & 0,2 & 0,8 & 0,2 & 1 & 0 & 0,8 & 0,3 & 0,8 & 0,3 & 0,8 & 0,2 \\
\hline & Kan Ban & 0,8 & 0,2 & 0,7 & 0,3 & 0,8 & 0,2 & 0,8 & 0,2 & 0,7 & 0,3 & 0,8 & 0,2 & 0,8 & 0,2 \\
\hline \multirow{2}{*}{ Quality } & Quality System & 0,8 & 0,2 & 0,8 & 0,4 & 0,8 & 0,2 & 0,8 & 0,2 & 0,8 & 0,3 & 0,8 & 0,2 & 0,8 & 0,1 \\
\hline & Statistic Process Control & 0,8 & 0,2 & 0,8 & 0,2 & 0,8 & 0,2 & 1 & 0 & 0,9 & 0,3 & 0,9 & 0,2 & 0,8 & 0,2 \\
\hline \multirow{2}{*}{ Purchasing } & Just In Time & 0,9 & 0,2 & 0,8 & 0,3 & 0,8 & 0,2 & 1 & 0 & 0,8 & 0,2 & 1 & 0 & 1 & 0 \\
\hline & PPC & 0,8 & 0,2 & 0,8 & 0,2 & 0,8 & 0,2 & 0,8 & 0,2 & 0,8 & 0,2 & 1 & 0 & 0,8 & 0,2 \\
\hline
\end{tabular}

According to the conjunction criterion, among specialists of different areas, we have:

Fig. 3. Center of Gravity Scenario
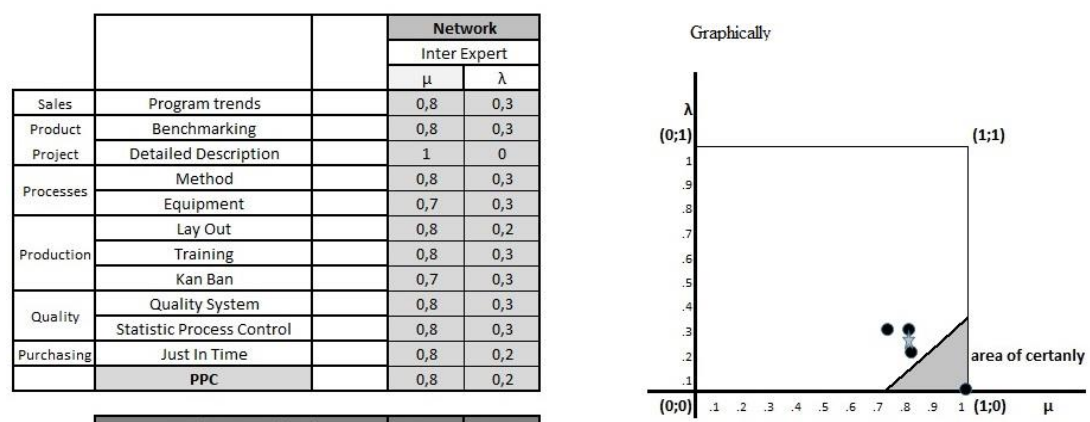

The Center of Gravity, the total effect of the knots, or the center of gravity of the network, comes up as plan $(0,80 ; 0,25)$.

It was verified that the center of gravity is not in the region of the desired, as it is not on the region of certainty.

As the objective of Planning is to determine a scenario that makes sure that the task will be performed, individually each factor of lesser certainty was re-analyzed, in 
order to come up with the global result desired by Planning, that is, right on the area where $\mathrm{H} \geq 0,7$.

The chosen factors were Training, KanBan, Quality System, SPC. These factors were chosen based on the notations and comments presented by the specialists when answering the questions.

The Training that had the matrix $\mathrm{p}_{\text {train }}(0,8 ; 0,3)$, was based on eventual training programs, which, although not leading to a $100 \%$ certainty, can be effective as far as the workforce involved in Production. New matrix $p_{\text {train }}(0,9 ; 0)$.

KanBan had a matrix $\mathrm{p}_{\mathrm{kan}}(0,7 ; 0,3)$; the system analyzed was in the installation process, it was only partially installed. As the installation experience was being positive, total installation was decided. New matrix $\mathrm{p}_{\text {kan }}(1 ; 0)$.

The Quality System had a matrix $p_{\text {qual }}(0,8 ; 0,3)$; it was a system in the installation process; it was installed only partially. As the installation experience was positive; it was totally installed. New matrix $\mathrm{p}_{\text {qual }}(1 ; 0)$.

SPC which had a matrix $\mathrm{p}_{\mathrm{spc}}(0,8 ; 0,3)$ was also being installed, with the same characteristics of the two other items; total installation was decided. The factors chosen for modification in order to achieve the desired result were based on the criteria of lower investment to achieve a combination of $\mu$ and $\lambda$. In this work was done using the comparison of the most critical items.

New matrix $\mathrm{p}_{\mathrm{spc}}(1 ; 0)$.

Other factors, for example, Equipments, also had a low matrix of certainty $\mathrm{P}_{\text {equip }}(0,7 ; 0,3)$ : it was considered poorly updated; however a decision to bring it up to date would demand a considerable investment and a long installation period - the decision was not to improve this item. Revised planning altered items:

Fig. 4. Revised Planning

\begin{tabular}{|c|c|c|c|c|c|c|}
\hline \multirow{2}{*}{ Production } & Training & & 0,8 & 0,3 & $\mathbf{0 , 9}$ & $\mathbf{0 , 1}$ \\
\hline & Kan Ban & & 0,7 & 0,3 & $\mathbf{1}$ & $\mathbf{0}$ \\
\hline \multirow{2}{*}{ Quality } & Quality System & & 0,8 & 0,3 & $\mathbf{1}$ & $\mathbf{0}$ \\
\hline & Statistic Process Control & & 0,8 & 0,3 & $\mathbf{1}$ & $\mathbf{0}$ \\
\hline
\end{tabular}

Fig. 5. Revised Center of Gravity Scenario
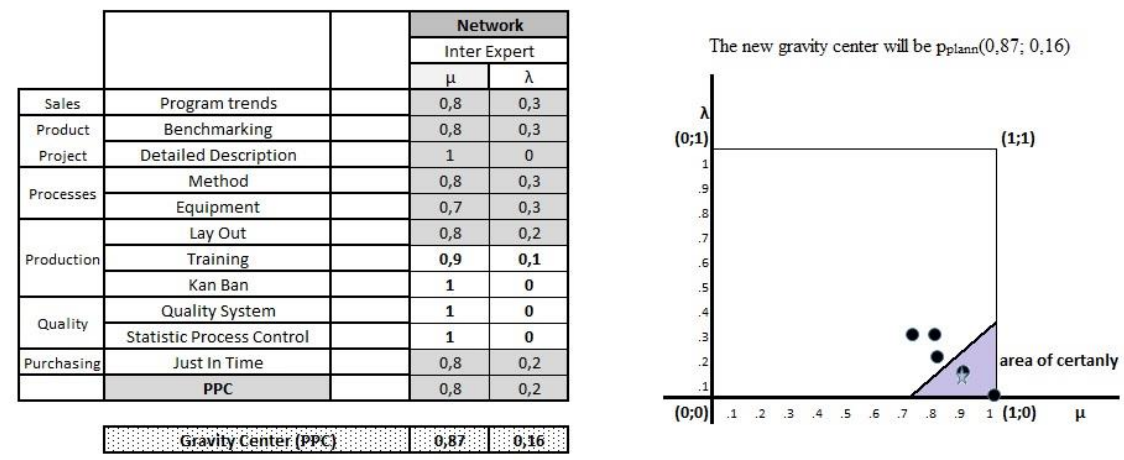


\section{Conclusion}

Paraconsistent logic offers a tool for analysis, which, through the concept of interorganizational network, guides for attaining the desired scenario, even when some factors or premises are not ideal.

Even when the present scenario does not reach the desired objectives, a reevaluation may lead to changes, through the adjustment of a few items, thus obtaining a scenario within the expected indicators.

It is important to notice that the questions that were brought up are based on the control of premises, that is, planning is only well managed when the execution of its parameters are being controlled.

In the next paper, we will research the reanalysis of factors for the modification of anactual scenario, using paraconsistent logic and presenting it through a mathematical frame.

Still on this line of thought, we shall research how paraconsistent logic can be used for Production Control, and together with the present work, we intend to present Planning and Production Control according to this logic.

\section{Reference}

[1] NEIL A. ERNST, ALEXANDER BORGIDA B., IVAN J. JURETAC , MYLOPOULOS J. - Agile requirements engineering via paraconsist reasoning - Journal homepage: www.elsevier.com/locate/infosys(2014).

[2]KAJIKAWA, Y. TAKEDA, I., MATSUSHIMA, K. - "Multiscale analysis of interfirm networks in regional clusters", Technovation 30 (2010)

[3] VOLLMANN, T.E.; BERRY, W.L.; WHYBARK, D.C.; JACOBS, F.R. - Sistemas de planejamento e controle da produção. Porto Alegre: Bookman, (2006).

[4] BEHBOUDI ASLA M.; KHALILZADEH A.;YOUSHANLOUE H.R.; MOOD M.M.; Identifying and ranking the effective factors on selecting Enterprise Resource Planning (ERP) system using the combined Delphi and Shannon Entropy approach, Tehran, (2012).

[5]MIZRUCHI, M.S. Análise de redes sociais: avanços recentes e controvérsias atuais. Revista de Administração de Empresas, v. 46, n. 3, p. 10-15, (2006).

[6] PRZEMYSŁAWRÓZEWSKI A., JAROSŁAW JANKOWSKI A., PIOTR BRÓDKA B., RADOSŁAW MICHALSKI B. - Knowledge workers' collaborative learning behavior modeling in an organizational social network - Journal homepage:www.elsevier.com/locate/comphumbeh(2015).

[7]JOHN QI DONG A., CHIA-HAN YANG - Information technology and organizational learning in knowledge alliances and networks: Evidence from U.S. pharmaceutical industry- Journal home page: www.elsevier.com/locate/im(2015).

[8]DE CARVALHO, F.R. -Tomadas de Decisão com Ferramentas da Lógica Paraconsistente Anotada, 2011. Editora Blucher, São Paulo. 